\title{
Expression of Cyclooxygenase-2, Nitric Oxide Synthase 2 and Heme Oxygenase-1 mRNA Induced by Bis-Eugenol in RAW264.7 Cells and their Antioxidant Activity Determined Using the Induction Period Method
}

\author{
YUKIO MURAKAMI, AKIFUMI KAWATA and SEIICHIRO FUJISAWA \\ Division of Oral Diagnosis and General Dentistry, Department of Diagnostic and Therapeutic Sciences, \\ Meikai University School of Dentistry, Sakado, Japan
}

\begin{abstract}
Background/Aim: To clarify the mechanisms responsible for the anti-inflammatory/proinflammatory activities of eugenol-related compounds, we investigated the cytotoxicity and up-regulatory/down-refgulatory effects of the biphenols curcumin, bis-eugenol, magnolol and honokiol, and the monophenols eugenol and isoeugenol, on major regulators of cyclooxygenase-2 (Cox-2), nitric oxide synthase 2 (Nos2) and heme oxygenase-1 (HO-1) mRNA in RAW264.7 cells. Materials and Methods: mRNA expression was investigated using real-time reverse transcriptasepolymerase chain reaction (RT-PCR), and the theoretical parameters were calculated using the DFT/B3LYP/6-31* method. Also, the antioxidant activity of eugenol-related compounds in combination with 2-mercapto-1methylimidazole (MMI, as a model for glutathione (GSH)) was investigated using the induction period method for polymerization of methyl methacrylate initiated by benzoyl peroxide (BPO). Results: The cytotoxicity of eugenol-related compounds showed a linear relationship with their softness $(\sigma)$ and electrophilicity $(\omega)$. At a concentration of $50 \mu \mathrm{M}$, biphenols except for bis-eugenol elicited the expression of mRNA for both Cox-2 and Nos2, but monophenols did not. In contrast, bis-eugenol elicited Cox-2 gene expression, but down-regulated Nos 2 gene expression. bis-Eugenol alone
\end{abstract}

This article is freely accessible online.

Correspondence to: Dr. Yukio Murakami, Division of Oral Diagnosis and General Dentistry, Department of Diagnostic and Therapeutic Sciences, Meikai University School of Dentistry, 1-1 Keyakidai, Sakado City, Saitama 350-0283, Japan. Tel: +81 492855511, Fax: +81 492876657, e-mail: ymura@dent.meikai.ac.jp

Key Words: Eugenol-related compounds, antioxidants, RAW264.7 cells, COX-2, NOS2, HO-1, theoretical parameters. induced the expression of HO-1 $\mathrm{mRNA}$, and when combined with MMI it showed a potent antagonistic effect on BPOinduced antioxidant activity. The ability of methoxyphenols to inhibit LPS-stimulated Cox-2 gene expression declined in the order curcumin $>>$ isoeugenol > bis-eugenol >> eugenol, and the rank of ability was related to their $\omega$ value. Conclusion: Most eugenol-related compounds had proinflammatory activity at high concentrations. However, they had also anti-inflammatory activity at lower concentrations. Eugenol-related compounds may exert antioxidant and anti-inflammatory activity in LPS-stimulated RAW264.7 cells possibly by inhibiting the activation of nuclear factor-kappa $B(N f-k B)$, whereas bis-eugenol requires induction of $\mathrm{HO}-1$ expression. bis-Eugenol as well as curcumin, may have anti-inflammatory and anticancer therapeutic applications.

Eugenol-related compounds are known to have antioxidant, anti-inflammatory, antiviral, antifungal, antibacterial, anticancer, antidiabetic and neuroprotective properties (1-3). We have previously shown that the biphenols curcumin, biseugenol, magnolol and honokiol exert antioxidant effects and also inhibit the up-regulation of cyclooxygenase-2 (Cox-2) mRNA expression elicited by lipopolysaccharide (LPS) and Porphyromonas gingivalis fimbriae (PGF) $(4,5)$. We have also shown that the prooxidant activity of eugenol, isoeugenol and curcumin is inhibited by visible light irradiation and treatment with horseradish peroxidase, suggesting that these compounds elicit production of intracellular reactive oxygen species (ROS) under prooxidative conditions (6-8). Interestingly, low and physiological levels of ROS are required for normal physiological activity in cells, whereas high levels of ROS promote cytotoxicity, apoptosis, and inflammatory activity. A high level of ROS modulates a number of cell signaling pathways, and regulates the expression of multiple genes such as Cox-2 and nitric oxide synthase (Nos) 2 in vitro and in vivo 
(9). The anti-inflammatory and anti-proliferative effects of curcumin and its related compounds are known to be induced through a ROS-independent mechanism (10). In general, inflammatory activity is accompanied by overexpression of inducible nitric oxide synthase (iNOS), leading to production of nitric oxide, which enhances the catalytic activity COX-2 via formation of the peroxinitrite anion (11). COX-2 is a downstream target of NOS2. Also, heme oxygenase-1(HO-1), the inducible isoform of $\mathrm{HO}$, catalyzes the degradation of heme into biliverdin, iron, and carbon monoxide (CO), and inhibits immune responses and inflammation in vivo. Biliverdin and bilirubin are potent antioxidants that attenuate oxidative stress. HO-1 has anti-inflammatory, antioxidant, and antiproliferative effects $(12,13)$, and is induced by oxidative stress.

In the present study, we investigated the cytotoxicity of ten eugenol-related compounds - eugenol, isoeugenol, bis-eugenol, curcumin, honokiol, magnolol, 4-cresol, 4-cresol dimer, 4methoxyphenol and 4-methoxyphenol dimer - for RAW264.7 cells using a Cell Counting Kit-8 (CCK-8) in relation to theoretical parameters such as softness $(\sigma)$, electrophilicity $(\omega)$ and the lowest unoccupied molecular orbital energy ( $\left.\mathrm{E}_{\mathrm{LUMO}}\right)$. Data on cytotoxicity and theoretical parameters had been obtained in our previous studies $(5,14)$. The parameters of some compounds were recalculated using the DFT/B3LYP/6$31 \mathrm{G}^{*}$ method. We also investigated whether eugenol-related compounds induced the expression of mRNAs for Nos 2, Cox2 and $H O-1$ in RAW264.7 cells, and the inhibitory effects of these compounds on Cox2-mRNA expression stimulated by LPS. Furthermore, to clarify the antioxidant activity of radicalmediated eugenol-related compounds in the presence of glutathione (GSH), a thiol, we investigated the antioxidant effect of eugenol-related compounds with or without 2mercapto-1-methylimidazole (MMI, a thiol). The antioxidant activity was evaluated by the induction period method using differential scanning calorimetry (DSC) monitoring of the polymerization of methyl methacrylate (MMA), initiated by thermal decomposition of $0.5 \mathrm{~mol} \%$ and $1 \mathrm{~mol} \%$ benzoyl peroxide (BPO, a $\mathrm{PhCOO}^{*}$ radical) under nearly anaerobic conditions (15). MMI was used as a model of GSH in our system because GSH is not soluble in MMA. The synergistic/ antagonistic interaction between eugenol-related compounds and MMI was studied using the induction period method, and the results were evaluated on the basis of bond dissociation enthalpy (BDE) difference, and $\triangle B D E$ between the BDE of eugenol-related compounds (O-H BDE) and that of cysteine (S-H BDE).

\section{Materials and Methods}

Materials. Eugenol (4-allyl-2-methoxyphenol), isoeugenol (4propenyl-2-methoxyphenol), MMA, BPO and MMI were purchased from Tokyo Kasei Co. (Tokyo, Japan). Curcumin, 1,7-bis (4hydroxy-3-methoxyphenol)-1,6-heptadiene-3,5-dione, was purchased from Wako Pure Chemical Industries, Ltd. (Osaka,
Japan). Magnolol (4-allyl-2-(5-allyl-2-hydroxy-phenyl) phenol) and honokiol (2-(4-hydroxy-3-prop-2-enyl-phenyl)-4-prop-2-enylphenol) were obtained from Kishida Chemical Industries, Ltd., Osaka, Japan. bis-Eugenol (3,3'-dimethoxy-5,5'-di-2-propenyl-1,1'biphenyl-2,2'-diol) was synthesized from eugenol monomers by the $\mathrm{CuCl}(\mathrm{OH})$-catalyzed ortho coupling reaction described previously (16). The chemical structures of these compounds are shown in Figure 1. Solutions of these compounds were prepared by dissolving each of them in dimethyl sulfoxide, followed by dilution to the indicated concentrations using serum-free RPMI-1640 (Invitrogen Co., Carlsbad, CA, USA) as test samples. Fetal bovine serum (FBS) was obtained from HyClone (Logan, UT, USA). Escherichia coli O111 B4-derived LPS was obtained from List Biological Laboratories, Inc. (Campbell, CA, USA).

Cell culture. The murine macrophage-like cell line RAW264.7, obtained from Dainippon Sumitomo Pharma Biomedical Co. Ltd. (Osaka, Japan), was used. The cells were cultured to a subconfluent state in RPMI-1640 medium supplemented with $10 \%$ FBS at $37^{\circ} \mathrm{C}$ and $5 \% \mathrm{CO}_{2}$ in air, washed, and then incubated overnight in serumfree RPMI-1640. They were then washed again and treated with the test samples.

Preparation of total RNA and real-time polymerase chain reaction $(P C R)$. The preparation of total RNA and the procedure for realtime PCR have been described previously (5). In brief, RAW264.7 cells in NUNC 96-flat-well-type microculture plates $\left(10^{5}\right.$ cells per well) were treated with the test samples. Total RNA was isolated using an RNeasy Plus Micro Kit (Qiagen Japan Co. Ltd., Tokyo, Japan) in accordance with the instruction manual. cDNA was synthesized from total RNA $(2 \mu \mathrm{g})$ of each sample by random priming using a High Capacity RNA-to-cDNA Kit (Life Technologies Japan, Tokyo, Japan). Reaction mixtures without the reverse transcriptase were used as a negative control. An aliquot of each cDNA synthesis reaction mixture was diluted and used for real-time PCR quantification. An equal-volume aliquot of each cDNA was mixed, serially diluted, and used as a standard. TaqMan probes/primers for Cox-2, Nos $2, H O-1$ and $18 s$ rRNA and the PCR enzyme mix for real-time PCR were purchased from Life Technologies Japan. Real-time PCR quantification was performed in triplicate using the GeneAmp Sequence Detection System 5700 software (Life Technologies Japan, Tokyo, Japan) in accordance with the instruction manual. The relative amount of target was calculated from standard curves generated in each PCR, and quantitative data with a coefficient of variance $(\mathrm{CV})$ of less than $10 \%$ were used for further analyses. Each calculated amount of mRNA was standardized by reference to that for $18 \mathrm{~s}$ rRNA. Data are expressed as means of three independent experiments. Statistical analyses were performed using Student's $t$-test and one-way ANOVA.

Radical-scavenging activity. The induction time (IT) and initial rate of polymerization (propagation rate, $\mathrm{Rp}$ ) in the presence or absence of an antioxidant were determined by the induction period method reported previously $(15,17)$. In brief, the experimental resin consisted of MMA and BPO with or without additives. BPO was added at $0.5 \mathrm{~mol} \%$ and $1 \mathrm{~mol} \%$, and the additives were used at 0.01 mol\%. The mixture of eugenol-related compounds and MMI was prepared at a 1:1 molar ratio. Approximately $10 \mu \mathrm{l}$ of the experimental resin (MMA: 9.15-9.30 mg) was.loaded into an 
<smiles>C=CCc1ccc(O)c(OC)c1</smiles>

Eugenol<smiles>C/C=C/c1ccc(O)c(OC)c1</smiles>

Isoeugenol<smiles>COc1cc(/C=C/C(=O)/C=C(O)/C=C/c2ccc(O)c(OC)c2)ccc1O</smiles>

Curcumin<smiles>C=CCc1ccc(O)c(-c2cc(CC=C)ccc2O)c1</smiles>

Magnolol<smiles>C=CCc1ccc(O)c(-c2ccc(O)c(CC=C)c2)c1</smiles>

Honokiol<smiles>C=CCc1cc(OC)c(O)c(-c2cc(CC=C)cc(OC)c2O)c1</smiles>

bis-Eugenol

Figure 1. The chemical structures of eugenol, isoeugenol, curcumin, bis-eugenol, magnolol and honokiol.

aluminum sample container and sealed by applying pressure. The container was placed in a DSC (model DSC 3100; Mac Science Co., Tokyo, Japan) kept at $70^{\circ} \mathrm{C}$, and the thermal changes induced by polymerization were recorded for the appropriate periods. The heat due to the polymerization of MMA was $13.0 \mathrm{kcal} \mathrm{mol}^{-1}$. The conversion of all samples (\%) was calculated from the DSC thermograms using the integrated heat evoked by polymerization of MMA. The conversion value was 93.5-96.7\%. The IT and propagation rate $\left(\mathrm{Rp}_{\mathrm{inh}}\right)$ for eugenol-related compounds with or without MMI was calculated using time-exotherm and timeconversion curves. The procedure was similar to that reported previously $(15,17)$.

Measurement of the stoichiometric factor ( $n$ )

The $n$ value in Eq. (1) can be calculated from the induction time in the presence of inhibitors (antioxidants) as:

$$
n=\mathrm{R}_{\mathrm{i}}[\mathrm{IT}] /[\mathrm{IH}]
$$

where IT is the induction time in the presence of a phenolic inhibitor (IH). The number of moles of BPO radicals trapped by the antioxidant was calculated with respect to 1 mole of the inhibitor moiety. The initiation rate $\left(\mathrm{R}_{\mathrm{i}}\right)$ for $\mathrm{BPO}$ at $70^{\circ} \mathrm{C}$ was $2.28 \times 10^{-6} \mathrm{~mol}$ $1^{-1} \mathrm{~s}^{-1}$, calculated on the basis of $\mathrm{n}=2.0$ for 2,6-di-tert-butyl-4methoxyphenol (17).
The inhibition rate constant $\left(\mathrm{k}_{\mathrm{inh}}\right)$ is given by

$$
\mathrm{k}_{\mathrm{inh}} / \mathrm{k}_{\mathrm{p}}=\left([\mathrm{MMA}] /[\mathrm{IT}] \times\left[\mathrm{Rp}_{\mathrm{inh}}\right]\right)
$$

where $\mathrm{k}_{\mathrm{p}}$ is the propagation rate constant, and MMA, IT and $\mathrm{Rp}_{\mathrm{inh}}$ are defined above.

\section{Calculation}

The O-H BDE values for eugenol-related compounds were taken from the data reported previously (3). Those for magnolol and honokiol were recalculated as follows. Firstly, the lowest and second lowest energy conformers of both phenol derivatives and their phenoxyl radical species were identified as candidates for geometry optimization using a conformer search procedure employing Merck Molecular Mechanics force fields (MMFF) calculation. The tentative conformers were them optimized for geometry by the restricted or unrestricted hybrid Hartree-Fock DFT calculation for the phenols and the phenoxyl radicals in vacuo using B3LYP functional on the $6-31 \mathrm{G}^{*}$ basis set level to afford the respective energetic minimized structures (18):

\section{$\mathrm{O}-\mathrm{H}$ BDE$=\mathrm{Hr}+\mathrm{Hh}-\mathrm{Hp}$,}

where $\mathrm{Hr}$ is the enthalpy of the phenoxyl radical generated by $\mathrm{H}$ abstraction, $\mathrm{Hh}$ is the enthalpy of the hydrogen radical, and $\mathrm{Hp}$ is the enthalpy of the parent phenol. The energy values of both the 
highest occupied molecular orbital (HOMO) and the lowest unoccupied molecular orbital (LUMO) energy of eugenol-related compounds were taken from our previous reports (5). The O-H BDE values for curcumin, magnolol and honokiol were recalculated. Briefly, all of the molecular modeling and calculations were performed using the Spartan 10 for Windows software package (Wavefunction Inc., Irvine, CA, USA). Chemical hardness $(\eta)$ softness $(\sigma)$, electronegativity $(\chi)$ and electrophilicity $(\omega)$ and Koopman's theorem ionization potential (IP, I $\mathrm{E}_{\text {HOMO }}$ ) were calculated using equations $2-5$, respectively:

$$
\begin{aligned}
& \eta=\left(E_{\mathrm{LUMO}}-\mathrm{E}_{\mathrm{HOMO}}\right) / 2 \\
& \sigma=1 / \eta \\
& \chi=-\left(\mathrm{E}_{\mathrm{LUMO}}+\mathrm{E}_{\mathrm{HOMO}}\right) / 2 \\
& \omega=\chi^{2} / 2 \eta
\end{aligned}
$$

\section{Results}

Relationships between cytotoxicity and $\sigma, \omega$ or $E_{L U M O}$. Ten eugenol-related compounds - 4-cresol, 4-methoxyphenol and eugenol and their ortho dimers, curcumin, isoeugenol, magnolol and honokiol - were selected. The theoretical parameters and $50 \%$ cytotoxic concentrations $\left(\mathrm{LC}_{50}\right)$ are shown in Table I, respectively.

From the data in Table I, eqns. 7-9 were formulated:

$$
\begin{aligned}
& \log 1 / \mathrm{LC}_{50}=-3.5( \pm 0.5)+ \\
& 1.0( \pm 1.9) \sigma\left(\mathrm{n}=10, \mathrm{r}^{2}=0.78,\right. \\
& p<0.001) \\
& \log 1 / \mathrm{LC}_{50}=0.2( \pm 0.5)- \\
& 1.2( \pm 0.3) \mathrm{E}_{\mathrm{LUMO}}(\mathrm{n}=10, \\
& \left.\mathrm{r}^{2}=0.71, p<0.001\right) \\
& \log 1 / \mathrm{LC}_{50}=-1.1( \pm 0.6)+ \\
& 0.9( \pm 0.2) \omega(\mathrm{n}=10, \\
& \left.\mathrm{r}^{2}=0.65, p<0.001\right)
\end{aligned}
$$

The logarithm of $1 / \mathrm{LC}_{50}$ for eugenol-related compounds was linearly related to their softness $(\sigma), \mathrm{E}_{\mathrm{LUMO}}$ and electrophilicity $(\omega)$ values.

Cox-2, Nos 2 and HO-1 mRNA expression. First, we examined the expression of mRNAs for Cox-2 and Nos 2 in RAW264.7 cells after treatment with eugenol-related compounds at $0.1,50$ and $1000 \mu \mathrm{M}$. The results are shown in Figure 2A and B. Curcumin, eugenol and isoeugenol upregulated the expression of Cox-2 mRNA at the high concenration of $1000 \mu \mathrm{M}$. Isoeugenol at $1000 \mu \mathrm{M}$ elicited much higher Cox-2 mRNA expression than did eugenol or curcumin $(p<0.05)$ (Figure $2 \mathrm{~A})$. There was no significant difference between the effects of curcumin and eugenol. We also examined the expression Cox- 2 mRNA elicited by biseugenol, magnolol and honokiol at $1000 \mu \mathrm{M}$ (Figure 2B). bis-Eugenol and magnolol, but not honokiol, a stereo isomer of magnolol, up-regulated the expression of Cox-2 mRNA, but to a lesser degree than the monophenols and curcumin.
Table I. Theoretical parameters for eugenol-related compounds.

\begin{tabular}{lcccc}
\hline Compound $^{\mathrm{a}}$ & $\begin{array}{c}\mathrm{E}_{\mathrm{HOMO}}(\mathrm{eV})^{\mathrm{a}} \\
\text { Eugenol }\end{array}$ & $\begin{array}{c}\mathrm{E}_{\mathrm{LUMO}} \\
(\mathrm{eV})^{\mathrm{a}}\end{array}$ & $\mathrm{IP}(\mathrm{eV})$ & $\sigma(\mathrm{eV})$ \\
\hline Isoeugenol & -5.448 & 0.233 & 5.45 & 0.35 \\
bis-Eugenol & $-5.182^{\mathrm{b}}$ & $-0.429^{\mathrm{b}}$ & 5.18 & 0.42 \\
Curcumin & $-5.194^{\mathrm{c}}$ & $0.012^{\mathrm{c}}$ & 5.19 & 0.38 \\
Magnolol & $-5.267^{\mathrm{b}}$ & $-2.035^{\mathrm{b}}$ & 5.27 & 0.62 \\
Honokiol & -5.812 & -0.612 & 5.81 & 0.38 \\
4-Cresol & -5.506 & -0.498 & 5.51 & 0.4 \\
4-Cresol dimer & -5.741 & 0.068 & 5.74 & 0.34 \\
4-Methoxyphenol & -5.807 & -0.52 & 5.8 & 0.38 \\
4-Methoxyphenol dimer & -5.344 & 0.006 & 5.34 & 0.34 \\
& -0.579 & 0.09 & 5.79 & 0.38 \\
Compound & $\eta(\mathrm{eV})$ & $\chi(\mathrm{eV})$ & $\omega(\mathrm{eV})$ & $\mathrm{LC}_{50}(\mathrm{mM})^{\mathrm{a}}$ \\
\hline Eugenol & 2.84 & 2.61 & 1.2 & $0.31^{\mathrm{c}}$ \\
Isoeugenol & 2.38 & 2.81 & 1.66 & $0.02^{\mathrm{c}}$ \\
bis-Eugenol & 2.6 & 2.59 & 1.29 & $0.07^{\mathrm{c}}$ \\
Curcumin & 1.62 & 3.65 & 4.11 & $0.002^{\mathrm{c}}$ \\
Magnolol & 2.63 & 3.24 & 2 & 0.09 \\
Honokiol & 2.5 & 3 & 1.8 & 0.4 \\
4-Cresol & 2.904 & 2.832 & 1.39 & $2.0^{\mathrm{b}}$ \\
4-Cresol dimer & 2.673 & 3.164 & 1.893 & $0.6^{\mathrm{b}}$ \\
4-Methoxyphenol & 2.668 & 1.331 & $2.2^{\mathrm{b}}$ \\
4-Methoxyphenol dimer & 2.437 & 3.016 & 1.866 & $0.7^{\mathrm{b}}$ \\
\hline & & & & \\
& & & & \\
\hline
\end{tabular}

aTaken from Murakami et al. $(5,47)$; bTaken from Fujisawa and Kadoma (29); cThis work.

Note that the values were expressed relative to the normal control as 1 . Next, we investigated whether eugenol-related compounds up-regulated the expression of Nos 2 mRNA at $1000 \mu \mathrm{M}$. Eugenol, isoeugenol and curcumin up-regulated the expression of Nos 2 mRNA (Figure 3); bis-eugenol and magnolol also did so, but the effect was weaker than that of the monophenols or curcumin. Honokiol had no effect on Nos 2 mRNA expression. These effects were similar to those on Cox-2 mRNA expression (Figure 3). We then investigated the effects of eugenol-related compounds on Cox -2 and Nos 2 mRNA expression at the low concentration of $50 \mu \mathrm{M}$. Magnolol, honokiol and curcumin - and particularily magnolol - up-regulated the expression of Nos2, whereas bis-eugenol down-regulated it (Figure 4). Monophenols had no effect on Nos 2 mRNA expression. The effect of magnolol on Cox-2 and Nos 2 mRNA expression was greater than that observed for the positive control treated with LPS.

Next, we investigated the effects of eugenol-related compounds on HO-1 mRNA expression. The results are shown in Figure 5A and B. bis-Eugenol up-regulated the expression of $\mathrm{HO}-1 \mathrm{mRNA}$ at both $1000 \mu \mathrm{M}$ and $50 \mu \mathrm{M}$, whereas the other compounds had no effect at either of the 

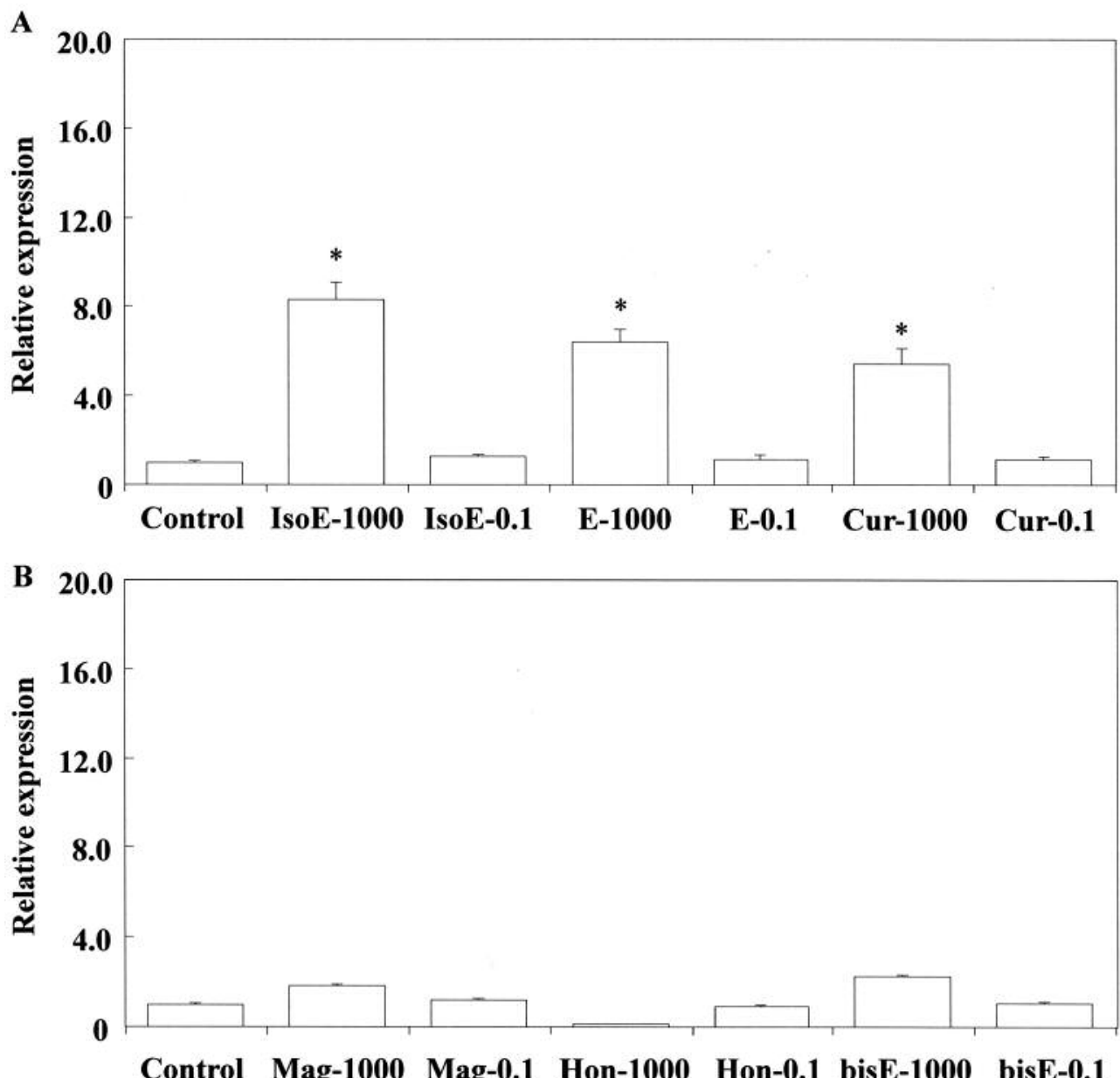

Figure 2. Stimulation of Cox-2 gene expression by isoeugenol, eugenol and curcumin (A), magnolol, honokiol and bis-eugenol (B) in RAW264.7 cells. The cells were incubated for $3.5 \mathrm{~h}$ with each eugenol-related compound at a concentration of $1000 \mu M$ or $0.1 \mu M$, and then their total RNAs were prepared. Each cDNA was synthesized, and the expression level of Cox-2 mRNA was determined by real-time PCR and standardized against the expression of $18 \mathrm{~s}$ rRNA. The results are presented as means \pm standard error (SE) of three independent experiments, SE $<15 \%$. Significant differences between samples for each eugenol-related compound were observed for stimulation of Cox-2 gene expression. * $p<0.01$ vs. control group.

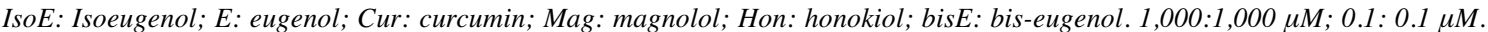

two concentrations. The up-regulatory effect on $\mathrm{HO}-1$ mRNA expression was observed in the absence of LPS. The gene expression was compared to that of the control untreated with the other compounds. Also, we investigated the effects of curcumin and isoeugenol on LPS-stimulated Cox-2 mRNA expression in RAW264.7 cells. The 50\% inhibitory concentration of curcumin was about $2 \mu \mathrm{M}$, whereas that of isoeugenol was about $22 \mu \mathrm{M}$ (Figure 6); those for bis-eugenol and eugenol were about $67 \mu \mathrm{M}$ and $310 \mu \mathrm{M}$, respectively. The $50 \%$ inhibitory concentrations of magnolol and honokiol for PGF-stimulated Cox-2 mRNA expression in RAW264.7 cells were about $9 \mu \mathrm{M}$ and $40 \mu \mathrm{M}$, respectively (Table I).
Radical-scavenging activity. The results are shown in Table I. Eugenol-related compounds act as chain-breaking inhibitors. The first reaction is the limiting step of chain termination. The rate and activation energy of the reactions depends on the dissociation enthalpy of the phenolic $\mathrm{OH}$ group (O-H BDE). Therefore, as a reference, the O-H BDE values for these compounds are also shown in Table II.

Using eq. (1), the $n$ value, i.e. the number of free radicals trapped by one mole of antioxidant moiety, was determined. The relative $n$ value declined in the order curcumin (3.9) > honokiol (3.2) > bis-eugenol (2.8) > isoeugenol (2.6) > magnol (2.2) > eugenol (1.5). In general, fully oxidized phenols with two $\mathrm{OH}$ groups in the molecule show an $n$ 

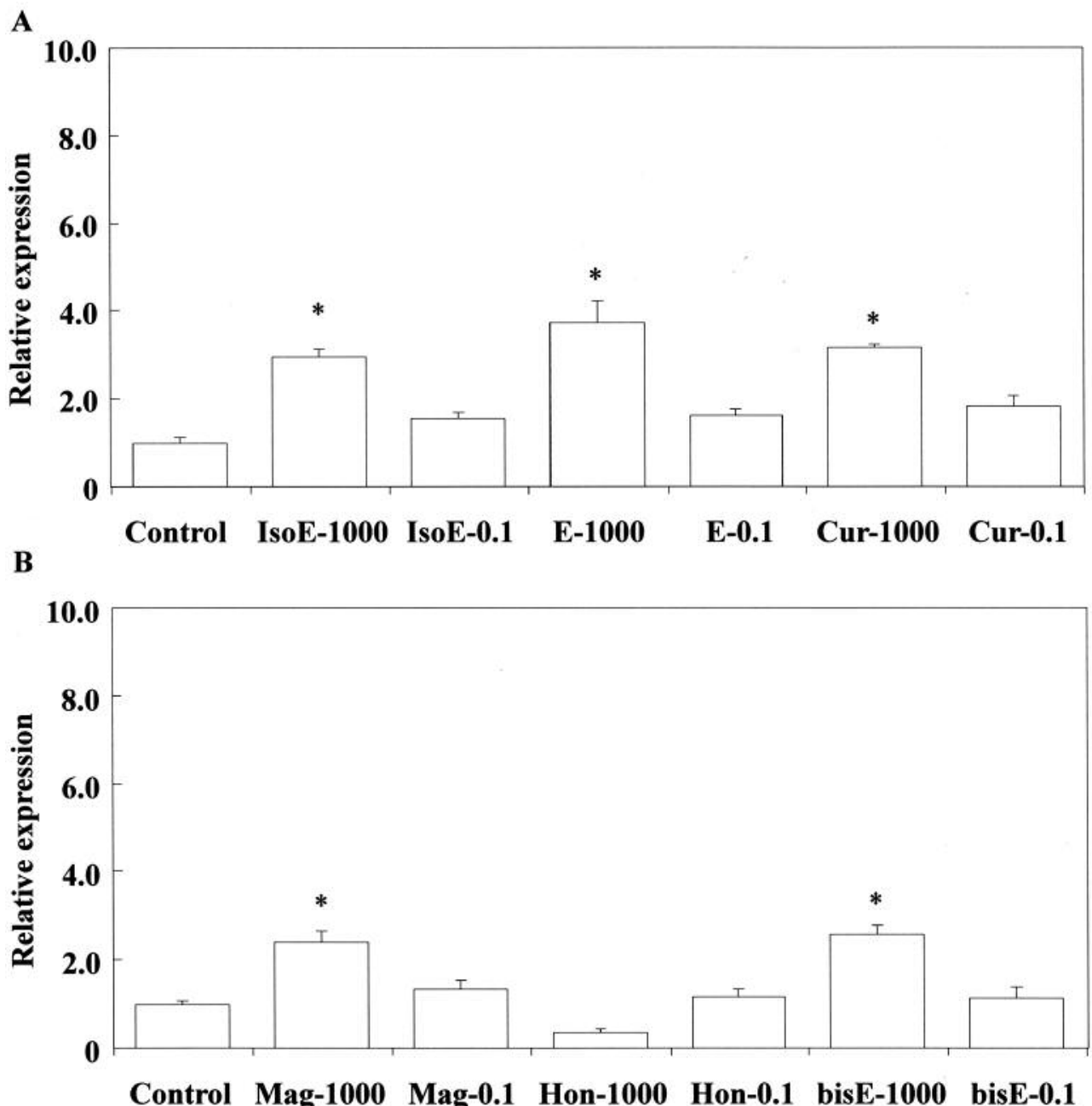

Figure 3. Stimulation of Nos2 gene expression by isoeugenol, eugenol and curcumin (A), magnolol, honokiol and bis-eugenol (B) in RAW264.7 cells. The cells were incubated for $3.5 \mathrm{~h}$ with each eugenol-related compound at a concentration of 1,000 $\mu M$ or $0.1 \mu M$, and then their total RNAs were prepared. Each cDNA was synthesized, and the expression level of Nos 2 mRNA was determined by real-time PCR and standardized against the expression of $18 \mathrm{~s} r R N A$. The results are presented as means \pm standard error (SE) of three independent experiments, SE $<15 \%$. Significant differences between samples for each eugenol-related compound were observed for stimulation of Nos 2 gene expression. *p<0.01 vs. control group. IsoE: Isoeugenol; E: eugenol; Cur: curcumin; Mag: magnolol; Hon: honokiol; bisE: bis-eugenol. 1,000:1,000 $\mu$ M; $0.1: 0.1 \mu M$.

value of 4 , whereas those with one $\mathrm{OH}$ group show an $n$ value of 2 . The $n$ value for eugenol and isoeugenol would be less than 2 , as their radical-scavenging activity is influenced by the intramolecular hydrogen bond formed between the phenolic $\mathrm{OH}$ and the adjacent methoxy groups $(19,20)$. However, in this study, the $n$ value of 2.6 for isoeugenol may have been due to the formation of products which themselves act as inhibitors. This would have led to higher $n$ values, which would vary according to the secondary nature of the reactions. Curcumin also has an intramolecular hydrogen bond between the phenolic $\mathrm{OH}$ and adjacent methoxy groups, but this compound showed an $n$ value of about 4 . In contrast, magnolol and honokiol, which are lignans with two phenolic OH groups, should have an $n$ value of 4 , but the actual value for magnolol was about 2 , suggesting that this may be responsible for the intramolecular hydrogen bond formed between the $\mathrm{OH}$ groups. For honokiol, a dimer of $p$ allylphenol and $o$-allylphenol, the phenolic $\mathrm{OH}$ group at the $o$-position is probably first abstracted by peroxy radicals, since its $\mathrm{O}-\mathrm{H}$ BDE is smaller than that of the $\mathrm{OH}$ group at the $p$-position (Table II). Honokiol can be fully oxidized via a two-electron process and is capable of having an $n$ value of 4 . Therefore, the radical-scavenging activity should be evaluated not only in terms of the $n$ value but also the 

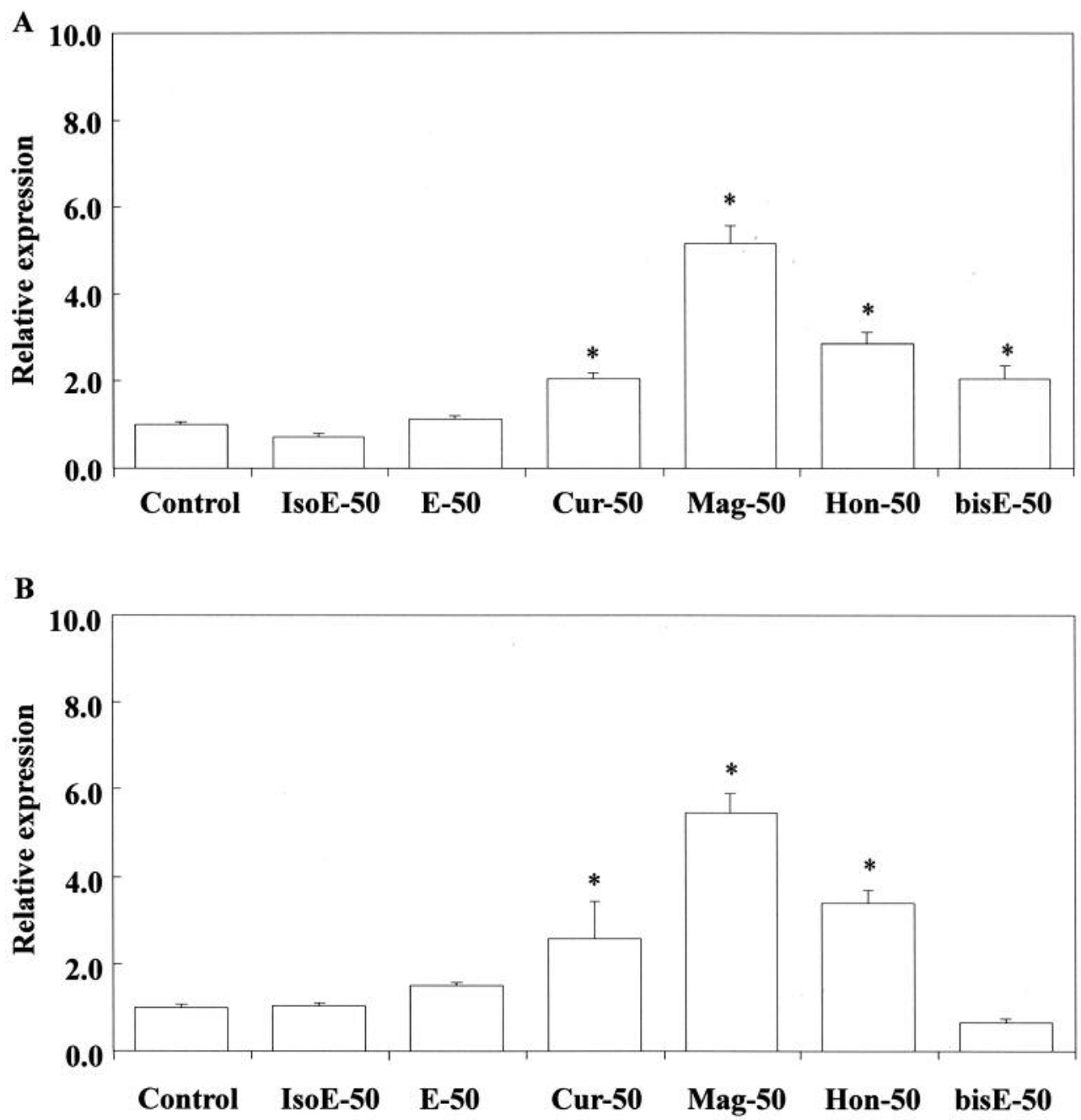

Figure 4. Stimulation of Cox-2 (A) and Nos2 (B) gene expression by isoeugenol, eugenol, curcumin, magnolol, honokiol and bis-eugenol in RAW264.7 cells. The cells were incubated for $3.5 \mathrm{~h}$ with each eugenol-related compound at a concentration of $50 \mu M$, and then their total RNAs were prepared. Each cDNA was synthesized, and the expression level of each mRNA was determined by real-time PCR and standardized against the expression of $18 s$ rRNA. The results are presented as means \pm standard error (SE) of three independent experiments, SE $<15 \%$. Significant differences between samples for each eugenol-related compound were observed for stimulation of each gene expression. *p<0.01 vs. control group. IsoE: Isoeugenol; E: eugenol; Cur: curcumin; Mag: magnolol; Hon: honokiol; bisE: bis-eugenol. 50:50 $\mu$ M.

inhibitory propagation rate. Eugenol-related compounds having an intramolecular hydrogen bond between the phenolic $\mathrm{OH}$ and adjacent methoxy groups suppressed the propagation rate in the presence of a phenolic inhibitor $\left(\mathrm{Rp}_{\mathrm{inh}}\right)$ (Table II). In contrast, the $\mathrm{Rp}_{\mathrm{inh}}$ for both magnolol and honokiol without methoxy groups was similar to the propagation rate of the control $\left(\mathrm{Rp}_{\mathrm{con}}\right)$. Thus, it was clarified that the Rp of eugenol, isoeugenol, bis-eugenol and curcumin is influenced by their methoxy groups. Using eq.2, $\mathrm{k}_{\mathrm{inh}} / \mathrm{k}_{\mathrm{p}}$ declined in the order eugenol (7.8) > magnolol (6.8) $>$ isoeugenol $(5.69)>$ honokiol $(4.8)>$ bis-eugenol $(4.6)>$ curcumin (3.7). The inhibition rate constant $\left(\mathrm{k}_{\mathrm{inh}}, \mathrm{mol}^{-1} \mathrm{~s}^{-1}\right)$ for honokiol, bis-eugenol and curcumin was less than that of eugenol, isoeugenol and magnolol, indicating that the former compounds scavenge radicals much more efficiently (see the $n$ value) whereas their radical trapping time is shorter than that of the latter.

Next, we investigated the effect of MMI on the antioxidant activity of eugenol-related compounds using the induction period method. MMI was used as a model of GSH. The results are also shown in Table I. The synergistic and antagonistic effects of these compounds were evaluated from 


\section{$\mathbf{A}$}
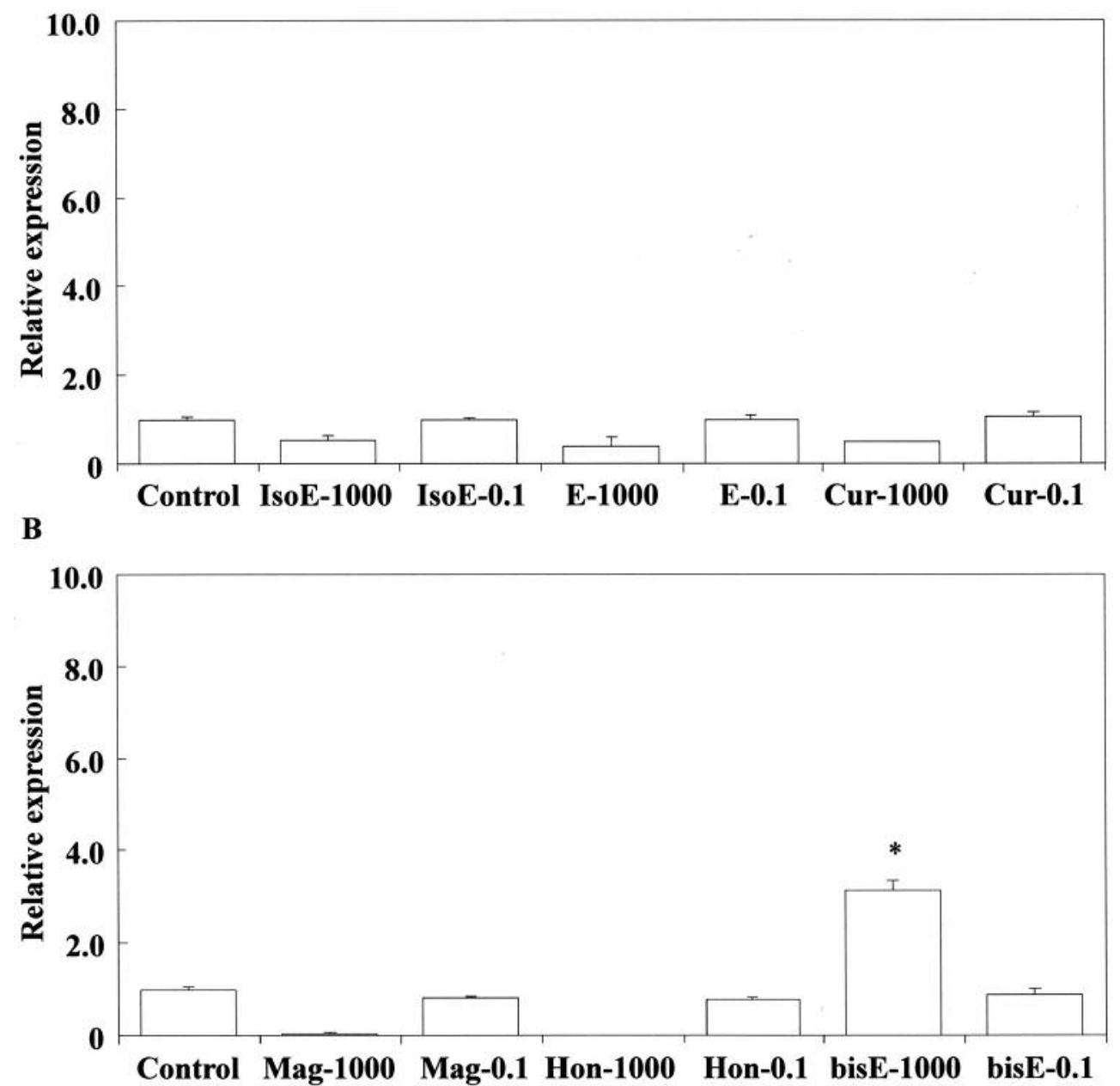

Figure 5. Stimulation of HO-1 gene expression by isoeugenol, eugenol and curcumin (A), magnolol, honokiol and bis-eugenol (B) in RAW264.7 cells. The cells were incubated for $3.5 \mathrm{~h}$ with each eugenol-related compound at a concentration of 1,000 $\mu M$ or $0.1 \mu M$, and then their total RNAs were prepared. Each CDNA was synthesized, and the expression level of HO-1 mRNA was determined by real-time PCR and standardized against the expression of $18 \mathrm{~s}$ rRNA. The results are presented as means \pm standard error (SE) of three independent experiments, SE $<15 \%$. Significant differences between samples for each eugenol-related compound were observed for stimulation of $\mathrm{HO}-1$ gene expression. ${ }^{*} p<0.01$ vs. control group. IsoE: Isoeugenol; E: eugenol; Cur: curcumin; Mag: magnolol; Hon: honokiol; bisE: bis-eugenol. 1,000:1,000 $\mu$ M; $0.1: 0.1 \mu M$.

the ratio of the IT values, i.e. the ratio of the IT for the eugenol-related compound/MMI mixture (1: 1 mole ratio) to that of a simple sum (eugenol-related compound + MMI). Antagonism (A), i.e. an IT ratio of $<1$, was observed for biseugenol and curcumin, and particularly the former. Weak but significant antagonism has also been observed previously for isoeugenol and curcumin (15). Conversely, eugenol showed an IT ratio of $>1$; indicating a synergistic (S) recycling effect. Such a recycling effect of eugenol has been reported previously $(20,21)$. A synergistic/antagonistic effect may be dependent on the $\triangle \mathrm{BDE}$ value, i.e. the difference of $\mathrm{BDE}$ between O-H BDE and S-H BDE. When the O-H BDE value of phenolic antioxidants approximates the S-H BDE value of $\mathrm{GSH}$, or when it is smaller than the S-H BDE value, synergism/antagonism can be explained by regeneration mechanisms (22). The $\triangle \mathrm{BDE}, \mathrm{O}-\mathrm{H} \mathrm{BDE}$ and $\mathrm{S}-\mathrm{H}$ BDE values for eugenol-related compounds are shown in Table III. The $\triangle \mathrm{BDE}$ value for eugenol was smaller than that for isoeugenol, and the $\triangle \mathrm{BDE}$ of bis-eugenol $\left(\Delta \mathrm{BDE}^{2 \mathrm{nd}}\right)$ was smaller than those for other biphenols. The smallest $\triangle \mathrm{BDE}^{2 \mathrm{nd}}$ observed for eugenol-dimer may be related to the large antagonistic effect of bis-eugenol with GSH in biological systems. The curcumin/MMI mixture also showed an antagonistic effect, but was less marked than that of the 
Table II. The antioxidant activity of the eugenol-related compound/2mercapto-1-methylimidazole, MMI mixture (1:1 molar ratio) determined by the induction period method for polymerization of methyl methacrylate (MMA) initiated by thermal decomposition of benzoyl peroxide (BPO). Effects of the antioxidant activity of eugenol-related compounds with or without MMI.

\begin{tabular}{lcccccc}
\hline Antioxidant & $\begin{array}{c}\mathrm{IT}^{\mathrm{b}} \\
(\mathrm{min})\end{array}$ & $n^{\mathrm{c}}$ & $\begin{array}{c}\left(\mathrm{Rp}_{\mathrm{inh}} /\right. \\
\left.\mathrm{Rp}_{\text {con }}\right)^{\mathrm{d}}\end{array}$ & $\begin{array}{c}\left(\mathrm{k}_{\text {inh }} /\right. \\
\mathrm{kp})^{\mathrm{e}}\end{array}$ & $\begin{array}{c}\text { IT } \\
\text { ratio }^{\mathrm{f}}\end{array}$ & Effect \\
\hline 0.5 mol\% BPO & & & & & & \\
MMI & 3.22 & 0.2 & 0.56 & - & - & - \\
Curcumin (CUR) & 56.51 & 3.9 & 0.54 & 3.73 & - & - \\
CUR/MMI & 58.62 & - & 0.56 & - & $0.98^{*}$ & $\mathrm{~A}$ \\
CUR + MMI & 59.73 & - & - & - & - & - \\
Eugenol (EUG) & 22.57 & 1.5 & 0.6 & 7.76 & - & - \\
EUG/MMI & 27.74 & - & 0.55 & - & $1.08^{* *}$ & $\mathrm{~S}$ \\
EUG + MMI & 25.78 & - & - & - & - & - \\
bisEUG & 40.34 & 2.8 & 0.57 & 4.58 & - & - \\
bisEUG/MMI & 37.28 & - & 0.57 & - & $0.86^{* *}$ & $\mathrm{~A}$ \\
bisEUG + MMI & 43.55 & - & - & - & - & - \\
& & & & & & \\
1.0 mol\% BPO & & & & & & - \\
MMI & 2.06 & 0.3 & 0.83 & - & - & - \\
IsoEUG & 18.87 & 2.6 & 0.93 & 5.63 & - & - \\
IsoEUG/MMI & 19.30 & - & 0.91 & - & $0.92^{\mathrm{h}}$ & $\mathrm{A}$ \\
Honokiol & 23.32 & 3.2 & 1.04 & 4.77 & - & - \\
Magnolol & 16.81 & 2.2 & 1.02 & 6.71 & - & - \\
\hline
\end{tabular}

The procedure is described in the text. Values are means of 2-3 samples. Standard error $<5 \%$. aEach, $0.01 \mathrm{~mol} \%$, approx. $1 \mathrm{mM}$; ${ }^{\mathrm{b}} \mathrm{IT}=\mathrm{IT}_{\mathrm{ob}}-$ $\mathrm{IT}_{\text {con; }}{ }^{\mathrm{c} S t o i c h i o m e t r i c}$ factor determined using eq. 1 ; ${ }^{\mathrm{d}}$ The ratio of the initial rate of polymerization in the presence of a phenolic inhibitor $\left(\mathrm{Rp}_{\mathrm{inh}}\right)$ to that of the control $\left(\mathrm{Rp}_{\mathrm{con}}\right)$; ${ }^{\mathrm{e}} \mathrm{The}$ ratio of the rate constant of

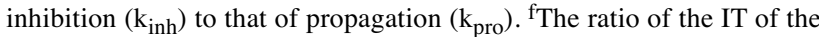
antioxidant/MMI mixture to that of the simple sum of the antioxidant and MMI; gEffects: A, antagonism $<1, \mathrm{~B}$, synergism $>1$; ${ }^{\text {hTaken from }}$ Fujisawa and Kadoma (15). ${ }^{*} p<0.05, * * p<0.01$.

bis-eugenol/MMI mixture. Phenoxyl radicals derived from peroxide-induced eugenol-related compound were reduced by interaction with MMI. In the last stage, eugenol-related compounds may be oxidized directly to quinone methides, possibly explaining their toxic effects and/or perhaps leading to formation of non-radical adducts. Isoeugenol also showed a relatively weak antagonistic effect, but greatly up-regulated Cox-2 and Nos 2 gene expression at higher concentrations. We previously synthesized the reaction products of isoeugenol with ethanethiol, thiophenol, 2-mercaptothiazoline or 2mercapto-1-methylimidazole in the presence of Lewis acid. Reaction products of isoeugenol bearing a SH group may tend to form via its radical-scavenging process because oxidation of isoeugenol produces a reactive benzyl radical as an intermediate (23). These findings suggest a possible interaction between biological macromolecules such as protein and DNA and isoeugenol, possibly resulting in allergens (24). In contrast, the $\mathrm{O}-\mathrm{H} \mathrm{BDE}^{2 \text { nd }}$ values of
Table III. Phenolic $O-H$ bond dissociation enthalpy $(O-H B D E)$ and the difference between the $O-H B D E$ of phenols and the $S-H B D E$ of cysteine, $\triangle B D E=[O-H B D E]-[S-H B D E]$.

\begin{tabular}{|c|c|c|c|}
\hline Phenolsa & No. OH & $\mathrm{BDE}\left(\mathrm{kJmol}^{-1}\right)$ & $\Delta \mathrm{BDE}\left(\mathrm{kJmol}^{-1}\right)$ \\
\hline Cys-SH ${ }^{b}$ & - & 356.2 & - \\
\hline $\mathrm{CH}_{3} \mathrm{~S}-\mathrm{H}^{\mathrm{c}}$ & - & Approx. 365.3 (expt.) & - \\
\hline Eugenol & 1 & 346.8 & -9.4 \\
\hline bis-Eugenol & 2 & $\begin{array}{c}336.5,1^{\text {st }} \mathrm{OH} \\
354.0,2^{\text {nd }} \mathrm{OH}\end{array}$ & $\begin{array}{l}-19.7 \\
-2.2\end{array}$ \\
\hline Isoeugenol & 1 & 339.2 & -17.0 \\
\hline Curcumin & 2 & $\begin{array}{l}344.0,1^{\text {st } O H} \\
347.0,2^{\text {nd }} \mathrm{OH} \\
345.1, o-\mathrm{OH} .\end{array}$ & $\begin{array}{l}-12.2 \\
-9.2\end{array}$ \\
\hline Honokiol $^{\mathrm{d}}$ & 2 & $\begin{array}{c}1^{\text {st } \mathrm{OH}} \\
355.4, p-\mathrm{OH} \\
373.4,2^{\text {nd }} \mathrm{OH}\end{array}$ & $\begin{array}{c}-11.1 \\
- \\
+17.0\end{array}$ \\
\hline Magnolol $^{\mathrm{d}}$ & 2 & $\begin{array}{l}328.0,1^{\text {st } O H} \\
381.0,2^{\text {nd }} \mathrm{OH}\end{array}$ & $\begin{array}{l}-28.2 \\
+24.8\end{array}$ \\
\hline
\end{tabular}

$\mathrm{BDE} 1^{\mathrm{st}} \mathrm{OH}$, the enthalpy required to generate a monoradical $(\mathrm{PhO} *)$; $\mathrm{BDE} 2{ }^{\mathrm{nd}} \mathrm{OH}$, the enthalpy required to generate a biradical $(* \mathrm{OPh}-\mathrm{PhO} *)$. aTaken from Kadoma et al. (29); b Taken from Rauk et al. (48); 'Taken from Franz et al. (49); d This work.

magnolol and honokiol were much higher than those of methoxyphenols such as curcumin and bis-eugenol, and also much higher than that of the S-H BDE for Cys-SH (Table III). Therefore, we did not study the antioxidant activity of the magnolol (or honokiol)/MMI mixture, as this would lead to possible additivity.

\section{Discussion}

According to Fukui's Frontier Orbital Theory (25), adduct formation occurs when a soft nucleophile denotes its highenergy electron to the empty lowest energy orbital (LUMO) of a soft electrophile. Therefore, the most relevant frontier orbital for electrophiles is the LUMO, whereas the HOMO is most important for nucleophiles (26). Softness is defined as the ease with which electron redistribution takes place during covalent bonding, and thus the softer the electrophile (more negative LUMO energy and higher $\sigma$ value), the more readily it will form an adduct by accepting an outer shell electron from a soft nucleophile such as a sulfur atom. With respect to covalent reactions, relative softness $(\sigma)$ reflects the ease with which electron redistribution occurs during adduct (covalent bond) formation. The softer the electrophile (large $\sigma$ and more negative LUMO value), the faster it will accept electron density from a donating nucleophile (27). Our results suggested that the cytotoxicity of eugenol-related compounds for RAW264.7 cells was linearly correlated with their $\sigma, \mathrm{E}_{\mathrm{LUMO}}$ and $\omega$ values. Therefore, the cytotoxicity of these compounds may be due 


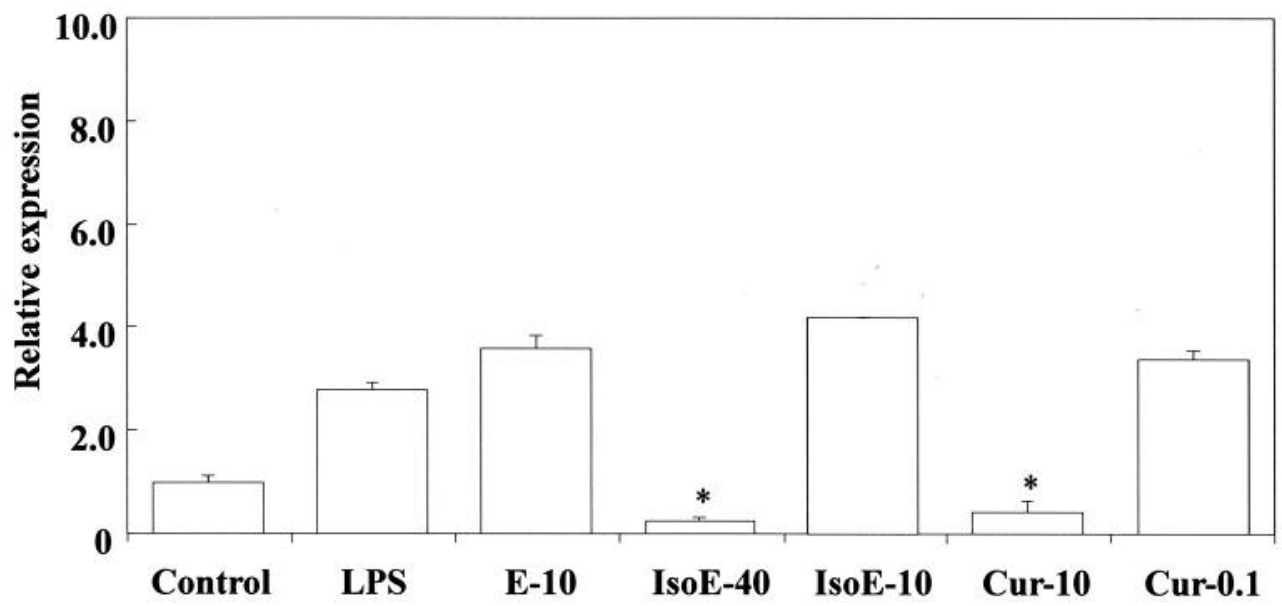

Figure 6. Inhibitory effects of isoeugenol and curcumin on LPS-stimulated Cox-2 gene expression in RAW264.7 cells. The cells were pretreated for $30 \mathrm{~min}$ with the indicated doses of isoeugenol, eugenol and curcumin. They were then incubated for $3 \mathrm{~h}$ with or without LPS at $100 \mathrm{ng} / \mathrm{ml}$, and their total RNAs were prepared. Each cDNA was synthesized, and the expression level of Cox-2 mRNA was determined by real-time PCR and standardized against the expression of $18 s$ rRNA. The results are presented as means \pm standard error (SE) of three independent experiments, $S E<15 \%$. Significant differences between samples for isoeugenol, eugenol and curcumin were observed for inhibition of Cox-2 gene expression. *p<0.01 vs. control group. IsoE: Isoeugenol; E: eugenol; Cur: curcumin. 40:40 $\mu \mathrm{M} ; 10: 10 \mu \mathrm{M} ; 0.1: 0.1 \mu \mathrm{M}$.

to their interaction with cellular GSH and macromolecules with sulfhydryl groups such as DNA and proteins. We previously reported that the cytotoxicity of eugenol-related compounds was linearly correlated with their $\eta$ value $(\sigma$ value) $(28,29)$. Also, the rank of the $50 \%$ effective concentration, $\mathrm{E}_{50}$, for the anti-inflammatory activity of methoxyphenols appeared to be dependent on their $\omega$ value. Similarly, we have previously reported that the antiinflammatory activity of eugenol-related compounds was related to their $\omega$ value, the former increasing as the $\omega$ value increased (30). Also, magnolol and honokiol have been shown to exert anti-inflammatory activity, the rank order being much lower than curcumin but higher than biseugenol, judged by the estimation of COX-2 inhibitory activity by basing the $\omega$ value of these compounds (3).

On the other hand, it is well known that free radicals such as the superoxide anion, hydroxy, alkyl, alkoxy, peroxy and nitric oxide radicals can emerge spontaneously and/or be generated through enzyme catalysis or in biological systems; eugenol-related compounds, which are chain-breaking antioxidants, preferably scavenge free radicals. Therefore, much interest has been focused on the antioxidant activity of eugenol-related compounds for prevention of radicalmediated inflammatory activity and diseases (3). The kinetic antioxidant activity of phenolic compounds was analyzed previously in terms of their ability to inhibit the oxidation of styrene by proxyl radicals generated from styrene by azo-bisisobutyronitrile, and these inhibitory effects were similar to those occurring in cells (31). We have also studied the kinetic antioxidant activity of methoxyphenols and tertbutylphenols using the induction period method for polymerization of MMA initiated by thermal decomposition BPO, and found a possible link between cytotoxicity in human gingival cells and the $\mathrm{k}_{\mathrm{inh}} / \mathrm{k}_{\mathrm{p}}$ values of these compounds; a certain correlation was evident between the logarithm of $\mathrm{k}_{\mathrm{inh}} / \mathrm{k}_{\mathrm{p}}$ and the O-H BDE value (29). These findings suggested that phenol-induced cytotoxicity may be due to radical-mediated mechanisms.

In the present study, eugenol-related compounds, particularly isoeugenol, eugenol and curcumin, up-regulated the expression of Cox-2 and Nos 2 mRNA at the high cytotoxic concentration of $1,000 \mu \mathrm{M}$. At $50 \mu \mathrm{M}$, magnolol, honokiol, curcumin and bis-eugenol, and particularly magnolol, up-regulated Cox-2 and Nos 2 gene expression to a greater degree than the monophenols, isoeugenol and eugenol. As biological systems are heterogeneous environments, hydrophobicity is a more desirable property than hydrophilicity. Therefore, biphenols with high hydrophobicity may have a more pronounced effect on gene expression than monophenols. The high expression of the Cox-2 and Nos 2 genes elicited by magnolol, which has an intramolecular hydrogen bond between the di-ortho-hydroxy groups, may have been caused by formation of its semiquinone radical (-OH-O*) and subsequent quinone methide formation (32). The rank order of O-H BDE ${ }^{1 \mathrm{st}}(\mathrm{eV})$ was honokiol (345) > curcumin $(344)>$ bis-eugenol $(337)>$ magnolol (328) (Table III). Magnolol may be preferentially oxidized due to its small $\mathrm{O}-\mathrm{H} \mathrm{BDE}^{1 \text { st }}$ value and its $n$ value 
was 1 , possibly resulting in the high expression of the Cox-2 and Nos 2 genes. Curcumin and bis-eugenol, and particularly the latter, showed a small BDE ${ }^{2 n d}=[\mathrm{O}-\mathrm{H}$ BDE $]-[\mathrm{S}-\mathrm{H}$ BDE $]$, possibly due to antagonistic effects occurring between the phenolic antioxidant and GSH. For GSH, co-antioxidant effects may up-regulate $\mathrm{HO}-1$ gene expression, although the mechanism remains unknown. GSH is well known to be an abundant thiol present in mammalian cells, performing a number of functions; it maintains the essential thiol-states of proteins by preventing oxidation of sulfhydryl groups or by reducing disulfide bonds induced by oxidative stress by scavenging free radicals $(33,34)$. The complex nature of electrophiles, which are reactive eugenol-related compounds, is illustrated by the fact that GSH is depressed by quinone methides, which are formed by radical oxidation of phenol (21). The toxic effects of eugenol are mediated through its quinone methide metabolite. Quinone methide formation by phenolic compounds is associated with both cytoprotective as well as cytotoxic effects (35). The biological targets of quinone methides derived from radical-oxidation of phenols could exert cytotoxic effects through covalent modification of biological macromolecules such as proteins and/or DNA, as well as depletion of GSH leading to an altered redox balance within cells (36). Alternatively, cytoprotection could occur due to formation of quinone methide through covalent modification of Kelch-like ECH-associated protein 1 (Keap1), leading to activation of nuclear factor erythroid 2related factor 2 (Nrf2) and subsequent induction of detoxification enzymes such as nicotinamide adenine dinucleotide phospho $(\mathrm{NAD}(\mathrm{P}) \mathrm{H})$ :quinone oxidoreductase (NQO1) and heme oxygenase (36).

COX-2 is selectively induced by proinflammatory cytokines at sites of inflammation, and NOS2 is involved in the inflammatory process (37). HO-1 is the inducible isoform of heme oxygenase that catalyzes the degradation of heme into biliverdin, iron, and carbon. HO-1 has also been shown to be an oxidative stress-responsive gene that may exert important roles in cytoprotection and the resolution of inflammation to maintain tissue homeostasis $(12,38)$. In most cell types, HO-1 is inducible by heme, radiation, cytokines, inflammatory stimuli, and oxidative and heat stress (39). Recent studies have demonstrated that overexpression of HO-1 prior to stimulation with LPS markedly inhibits the production of subsequent inflammatory mediators such as nitric oxide (NO), interleukin-6, and monocyte chemoattractant protein (MCP-1) (40, 41). Although, unlike nitric oxide $\left(\mathrm{NO}^{\circ}\right), \mathrm{CO}$ only weakly activates soluble guanylate cyclase, $\mathrm{CO}$ has been found to broadly suppress LPS-induced immediate-early genes that initiate and propagate inflammation involving pivotal transcription factors (e.g. ECG family members, Activating Transcription Factor 3) and cytokines (e.g. interleukin (IL)$1 \beta$, IL-8 and tumor necrosis factor (TNF)- $\alpha$ ) (42).
Our present study demonstrated that bis-eugenol downregulated the expression of the Nos 2 gene in RAW 264.7 cells. bis-Eugenol was able to suppress production of nitric oxide. It has also been reported that $\mathrm{CO}$ derived from $\mathrm{HO}-$ 1 may reduce the production of ROS and the function of NAPDH oxidase, as well as being a potent inhibitor of iNOS and Nf-kB (43). Many previous studies have indicated that curcumin affects $\mathrm{HO}-1$ expression in hepatoma cells (44) and fibroblasts (45), whereas magnolol does so in RAW264.7 cells (46). In the present study, however, none of the eugenol-related compounds except for bis-eugenol induced HO-1 expression in RAW264.7 cells. The signaling mechanisms involved in HO-1 expression may vary according to cell type and the inducers involved. LPS-stimulated expression of the Nos 2 gene in RAW264.7 cells was potently inhibited by bis-eugenol, but not by eugenol, whereas that of Tnf- $\alpha$ mRNA was not affected by $100 \mu \mathrm{M}$ bis-eugenol (data not shown). LPS-stimulated expression of Cox-2 mRNA was inhibited by eugenolrelated compounds, particularly curcumin, which had the highest $\omega$ value. This may also be related to the structure of biphenols and the $\alpha, \beta$-unsaturated carbonyl group of curcumin. Compounds like bis-eugenol, such as curcumin, magnolol and honokiol, preferentially suppress NfK-B activation, whereas bis-eugenol itself elicits a weak suppressive effect (5). In the present study, bis-eugenol required HO-1 mRNA expression. Magnolol has a biseugenol-like structure and has been reported to exhibit beneficial effects of treating bone diseases associated with excessive osteoclastogenesis (46); magnolol can increase HO-1 expression and Nrf2 activation in receptor activator of Nf-kB ligand (RANKL)-stimulated cells.

Our result strongly suggested that bis-eugenol may have therapeutic applications against inflammatory and anticancer activity via regulation of $\mathrm{HO}-1 \mathrm{mRNA}$. Despite the large disparity between experimental conditions and natural biological systems, studies of the kinetic and synergistic/ antagonistic antioxidant effects of eugenol-related compounds may help to explain the biphasic mechanism of the antioxidant/prooxidant activity. The toxicity of antioxidative eugenol-related compounds may be both intrinsic, and also attributable to metabolites such as quinonemethides, which have antioxidant-derived radicals (3). These phenolic compounds can exert multiple pharmacological functions through a single structure, involving radical-mediated dimer formation and quinonemethide formation. Therefore, theoretical parameters such as the $\sigma, \omega$ and O-H BDE values may be useful for predicting the anti-inflammatory/pro-inflammatory activity of eugenol-related compounds in biological systems. Further studies will be needed to clarify the mechanisms involved in the anti-inflammatory and pro-inflammatory activity of eugenol-related compounds. 


\section{Acknowledgements}

This work was supported by a grant-in-aid for scientific research (No.15K11266) from the Ministry of Education, Science, and Culture of Japan. The Authors would also like to thank Kadoma Y. and Ito S. for measurement of the induction time and calculations of theoretical parameters, respectively.

\section{References}

1 Moghadamtousi SZ, Kadir HA, Hassandarvish P, Tajik H, Abubakar S and Zandi K: A Review on Antibacterial, Antiviral, and Antifungal Activity of Curcumin. BioMed Research International Volume 2014: 186864, 2014.

2 Singh RP and Agarwal R: Mechanisms of action of novel agents for prostate cancer chemoprevention. Endocr Relat Cancer 13: 751-778, 2006.

3 Fujisawa S and Murakami Y: Eugenol and Its Role in Chronic Diseases. Adv Exp Med Biol 929: 45-66, 2016.

4 Murakami Y, Ishii H, Takada N, Tanaka S, Machino M, Ito S and Fujisawa S: Comparative anti-inflammatory activities of curcumin and tetrahydrocurcumin based on the phenolic $\mathrm{O}-\mathrm{H}$ bond dissociation enthalpy, ionization potential and quantum chemical descriptor. Anticancer Res 28: 699-707, 2008.

5 Murakami Y, Kawata A, Seki Y, Koh T, Yuhara K, Maruyama T, Machino M, Ito S, Kadoma Y and Fujisawa S: Comparative inhibitory effects of magnolol, honokiol, eugenol and biseugenol on cyclooxygenase-2 expression and nuclear factorkappa B activation in RAW264.7 macrophage-like cells stimulated with fimbriae of Porphyromonas gingivalis. In Vivo 26: 941-950, 2012.

6 Fujisawa S, Atsumi T, Ishihara M and Kadoma Y: Cytotoxicity, ROS-generation activity and radical-scavenging activity of curcumin andrelated compounds. Anticancer Res 24: 563-569, 2004.

7 Atsumi T, Tonosaki K and Fujisawa S: Induction of early apoptosis and ROS-generation activity in human gingival fibroblasts (HGF) and human submandibular gland carcinoma (HSG) cells treated with curcumin. Arch Oral Biol 51: 913-921, 2006.

8 Atsumi T, Murakami Y, Shibuya K, Tonosaki K and Fujisawa S: Induction of cytotoxicity and apoptosis and inhibition of cyclooxygenase- 2 gene expression, by curcumin and its analog, alpha-diisoeugenol. Anticancer Res 25: 4029-4036, 2005.

9 Zhang J, Wang X, Vikash V, Ye Q, Wu D, Liu Y and Dong W: ROS and ROS-Mediated Cellular Signaling. Oxid Med Cell Longev 2016: 4350965, 2016.

10 Sandur SK, Pandey MK, Sung B, Ahn KS, Murakami A, Sethi G, Limtrakul P, Badmaev V and Aggarwal BB: Curcumin, demethoxycurcumin, bisdemethoxycurcumin, tetrahydrocurcumin and turmerones differentially regulate antiinflammatory and anti-proliferative responses through a ROSindependent mechanism. Carcinogenesis 28: 1765-1773, 2007.

11 Salvemini D, Kim SF and Mollace V: Reciprocal regulation of the nitric oxide and cyclooxygenase pathway in pathophysiology: relevance and clinical implications. Am J Physiol Regul Integr Comp Physiol 304: R473-487, 2013.

12 Yamada N, Yamaya M, Okinaga S, Nakayama K, Sekizawa K, Shibahara S and Sasaki H: Microsatellite polymorphism in the heme oxygenase- 1 gene promoter is associated with susceptibility to emphysema. Am J Hum Genet 66: 187-195, 2000.

13 Gabunia K, Ellison SP, Singh H, Datta P, Kelemen SE, Rizzo V and Autieri MV: Interleukin-19 (IL-19) induces heme oxygenase-1 (HO-1) expression and decreases reactive oxygen species in human vascular smooth muscle cells. J Biol Chem 287: 2477-2784, 2012.

14 Kadoma Y, Murakami Y, Ogiwara T, Machino M, Yokoe I and Fujisawa S: Radical-scavenging activity and cytotoxicity of $p$ methoxyphenol and $p$-cresol dimers. Molecules 15: 1103-1112, 2010.

15 Fujisawa S and Kadoma Y: Anti- and pro-oxidant effects of oxidized quercetin, curcumin or curcumin-related compounds with thiols or ascorbate as measured by the induction period method. In Vivo 20: 39-44, 2006.

16 Satoh K, Sakagami H, Yokoe I, Kochi M and Fujisawa S: Interaction between eugenol-related compounds and radicals. Anticancer Res 18: 425-428, 1998.

17 Kadoma Y and Fujisawa S: Comparative radical-scavenging activity of curcumin and tetrahydrocurcumin with thiols as measured by the induction period method. In Vivo 21: 979-982, 2007.

18 Kadoma Y, Ito S, Atsumi T and Fujisawa S: Mechanisms of cytotoxicity of 2- or 2,6-di-tert-butylphenols and 2methoxyphenols in terms of inhibition rate constant and a theoretical parameter. Chemosphere 74: 626-632, 2009.

19 Ogata M, Hoshi M, Urano S and Endo T: Antioxidant activity of eugenol and related monomeric and dimeric compounds. Chem Pharm Bull (Tokyo) 48: 1467-1469, 2000.

20 Fujisawa S, Atsumi T, Kadoma Y and Sakagami H: Antioxidant and prooxidant action of eugenol-related compounds and their cytotoxicity. Toxicology 177: 39-54, 2002.

21 Thompson DC, Barhoumi R and Burghardt RC: Comparative toxicity of eugenol and its quinone methide metabolite in cultured liver cells using kinetic fluorescence bioassays. Toxicol Appl Pharmacol 149: 55-63, 1998.

22 Peyrat-Maillard MN, Cuvelier ME and Berset C: Antioxidant activity of phenolic compounds in 2, 2'-azobis (2amidinopropane) dihydrochloride (AAPH)-induced oxidation: synergistic and antagonistic effects. J Am Oil Chem Soc 80: 1007-1012, 2003.

23 Kadoma Y, Atsumi T, Okada N, Ishihara M, Yokoe I and Fujisawa S: Radical-scavenging activity of natural methoxyphenols $v s$. synthetic ones using the induction period method. Molecules 12: 130-138, 2007.

24 Tanaka S, Royds C, Buckley D, Basketter DA, Goossens A, Bruze M, Svedman C, Menné T, Johansen JD, White IR and McFadden JP: Contact allergy to isoeugenol and its derivatives: problems with allergen substitution. Contact Dermatitis 51: 288291, 2004.

25 Fukui K, Yonezawa T and Shingu H: A Molecular Orbital Theory of Reactivity in Aromatic Hydrocarbons. J Chem Phys 20: 722-725, 1952.

26 Cerda-Monje A, Ormazábal-Toledo R, Cárdenas C, Fuentealba $\mathrm{P}$ and Contreras R: Regional electrophilic and nucleophilic Fukui functions efficiently highlight the Lewis acidic/basic regions in ionic liquids. J Phys Chem B 118: 3696-3701, 2014.

27 LoPachin RM and Gavin T: Molecular mechanism of acrylamide neurotoxicity: lessons learned from organic chemistry. Environ Health Perspect 120: 1650-1657, 2012. 
28 Fujisawa S, Ishihara M, Murakami Y, Atsumi T, Kadoma Y and Yokoe I. Predicting the biological activities of 2-methoxyphenol antioxidants: effects of dimers. In Vivo 21: 181-188, 2007.

29 Fujisawa S and Kadoma Y: Relationship between phenolinduced cytotoxicity and experimental inhibition rate constant or theoretical parameter. Mini Rev Med Chem 12: 477-490, 2012.

30 Kadoma Y, Murakami Y, Atsumi T, Ito S and Fujisawa S: Cloves (Eugenol). In: Molecular targets and therapeutic uses of species: Modern uses for ancient medicine. Aggarwal BB and Kunnumakkara AB (eds.). Singapore, World Scientific, pp. 117$148,2009$.

31 Burton GW, Doba T, Gabe E, Hughes L, Lee FL, Prasad L and Ingold KU: Autoxidation of biological molecules. 4. Maximizing the antioxidant activity of phenols. J Am Chem Soc 107: 7053$7065,1985$.

32 Amorati R, Zotova J, Baschieri A and Valgimigli L: Antioxidant Activity of Magnolol and Honokiol: Kinetic and Mechanistic Investigations of Their Reaction with Peroxyl Radicals. J Org Chem 80: 10651-10659, 2015.

33 Galati G, Sabzevari O, Wilson JX and O'Brien PJ: Prooxidant activity and cellular effects of the phenoxyl radicals of dietary flavonoids and other polyphenolics. Toxicology 177: 91-104, 2002.

34 Rahman K: Studies on free radicals, antioxidants, and co-factors. Clin Interv Aging 2: 219-236, 2007.

35 Guyton KZ, Thompson JA and Kensler TW: Role of quinone methide in the in vitro toxicity of the skin tumor promoter butylated hydroxytoluene hydroperoxide. Chem Res Toxicol 6 : 731-738, 1993.

36 Bolton JL: Quinone Methide Bioactivation Pathway: Contribution to Toxicity and/or Cytoprotection? Curr Org Chem 18: 61-69, 2014.

37 Tracey KJ and Cerami A: Tumor necrosis factor: a pleiotropic cytokine and therapeutic target. Annu Rev Med 45: 491-503, 1994.

38 Gabunia K, Ellison SP, Singh H, Datta P, Kelemen SE, Rizzo V and Autieri MV: Interleukin-19 (IL-19) induces heme oxygenase-1 (HO-1) expression and decreases reactive oxygen species in human vascular smooth muscle cells. J Biol Chem 287: 2477-2484, 2012.

39 Koike A, Minamiguchi I, Fujimori K and Amano F: Nitric oxide is an important regulator of heme oxygenase- 1 expression in the lipopolysaccharide and interferon- $\gamma$-treated murine macrophagelike cell line J774.1/JA-4. Biol Pharm Bull 38: 7-16, 2015.

40 Tsoyi K, Kim HJ, Shin JS, Kim DH, Cho HJ, Lee SS, Ahn SK, Yun-Choi HS, Lee JH, Seo HG and Chang KC: HO-1 and JAK2/STAT-1 signals are involved in preferential inhibition of iNOS over COX-2 gene expression by newly synthesized tetrahydroisoquinoline alkaloid, CKD712, in cells activated with lipopolysacchride. Cell Signal 20: 1839-1847, 2008.
41 Park PH, Kim HS, Jin XY, Jin F, Hur J, Ko G and Sohn DH: KB-34, a newly synthesized chalcone derivative, inhibits lipopolysaccharide-stimulated nitric oxide production in RAW264.7 macrophages via heme oxygenase-1 induction and blockade of activator protein-1. Eur J Pharmacol 606: 215-224, 2009.

42 Chhikara M, Wang S, Kern SJ, Ferreyra GA, Barb JJ, Munson PJ and Danner RL: Carbon monoxide blocks lipopolysaccharideinduced gene expression by interfering with proximal TLR4 to NF-kappaB signal transduction in human monocytes. PLoS One 4(12): e8139, 2009.

43 Sun B, Sun Z, Jin Q and Chen X: CO-releasing molecules (CORM-2)-liberated $\mathrm{CO}$ attenuates leukocytes infiltration in the renal tissue of thermally injured mice. Int J Biol Sci 4: 176-183, 2008.

44 McNally SJ, Harrison EM, Ross JA, Garden OJ and Wigmore SJ: Curcumin induces heme oxygenase 1 through generation of reactive oxygen species, p38 activation and phosphatase inhibition. Int J Mol Med 19: 165-172, 2007.

45 Scharstuhl A, Mutsaers HA, Pennings SW, Szarek WA, Russel FG and Wagener FA: Curcumin-induced fibroblast apoptosis and in vitro wound contraction are regulated by antioxidants and heme oxygenase: implications for scar formation. J Cell Mol Med 13: 712-725, 2009.

$46 \mathrm{Lu} \mathrm{SH}$, Chen TH and Chou TC: Magnolol Inhibits RANKLinduced osteoclast differentiation of RAW264.7 macrophages through heme oxygenase-1- dependent inhibition of NFATc1 expression. J Nat Prod 78: 61-68, 2015.

47 Murakami Y, Kawata A, Ito S, Katayama T and Fujisawa S: Inhibitory effects of $p$-cresol and $p$-hydroxy anisole dimers on expression of the cyclooxygenase- 2 gene and lipopolysaccharide-stimulated activation of nuclear factor- $\mathrm{kB}$ in RAW264.7 cells. In Vivo 28: 719-725, 2014.

48 Rauk A, Yu D and Armstrong DA: Oxidative Damage to and by Cysteine in Proteins: An ab Initio Study of the Radical Structures, $\mathrm{C}-\mathrm{H}, \mathrm{S}-\mathrm{H}$, and $\mathrm{C}-\mathrm{C}$ Bond Dissociation Energies, and Transition Structures for H Abstraction by Thiyl Radicals. J Am Chem Soc 120: 8848-8855, 1998.

49 Franz JA, Dupuis M, Camaioni DM and Birnbaum J: A density functional theoretical study of S-H bond strengths in organic thiols and a model MoS cluster. Prepr Pap Am Chem Soc Div Fuel Chem 48: 621-622, 2003.
Received May 19, 2017

Revised June 5, 2017

Accepted June 6, 2017 